\title{
Education levels and survival in colorectal cancer: is there really an obvious association?
}

\author{
Bruna Valiati ${ }^{1,2}$, Rodrigo Oliva Perez ${ }^{1,2}$, Paulo Gustavo Kotze ${ }^{3}$ \\ ${ }^{1}$ Angelita e Joaquim Gama Institute, São Paulo; ${ }^{2}$ Department of Surgical Oncology, Hospital da Beneficiência Portuguesa, São Paulo; \\ ${ }^{3}$ Colorectal Surgery Unit, Catholic University of Paraná (PUCPR), Curitiba, Brazil
}

\section{Article: Factors associated with the survival of colorectal cancer in Mexico (Intest Res 2020;18:315-324)}

The association between education level and colorectal cancer outcomes has been a matter of interest for a long time. Even though a direct cause-consequence relationship between education and cancer treatment outcome is not necessarily present, low levels of education may ultimately be a surrogate marker for multiple features that may directly or indirectly affect colorectal cancer survival. In one interesting study, educational attainment was inversely associated with mortality from cancer, considering lung, breast, prostate, and colorectal cancer. In Australia, where there is a universal health system, subjects with colorectal cancer and higher level of education had $26 \%$ lower risk of dying from the disease. ${ }^{2}$

In the present issue of Intestinal Research, Quezada-Gutiérrez et al. ${ }^{3}$ report on a retrospective review of risk factors for worse survival in patients with colorectal cancer from a tertiary center in Mexico. The reported results indicate an independent association between low levels of education (schooling) and clinical disease stage with overall survival.

Even though this retrospective study comprises a significant sample of patients with an adequate follow-up after treatment, several issues should be considered before full interpretation of these findings that can ultimately embark on action to at-

Received June 1, 2020. Accepted June 5, 2020

Correspondence to Paulo Gustavo Kotze, Colorectal Surgery Unit, Catholic University of Paraná (PUCPR), Rua Bruno Filgueira, 369 - cj. 1205, Curitiba 80440-220, Brazil. Tel: +55-41-3243-0033, Fax: +55-41-3243-0033, E-mail: pgkotze@hotmail.com tempt to improve oncological outcomes in colorectal cancer in a population-based level.

First, being a surrogate marker suggests that education itself may not have accounted for the actual outcomes observed here. Low levels of education may be a marker for many other suboptimal conditions that may affect survival in colorectal cancer treatment. These conditions associated with low levels of education may include worse access to general health services, support to chronic associated health conditions, nutritional status and socioeconomical levels, among many other factors frequently observed in Latin American countries. Teasing out the exact contribution of each of these unfavorable features may be significantly challenging in this setting.

Second, the population of the study is highly heterogeneous in terms of disease stage and the therapeutic actions offered. Patients were simply grouped together whether surgery was performed or not, irrespective of what type of the exact surgical procedure or even precise pathological outcomes, which are known to be the main drivers of survival rates. In addition, the inclusion of stage IV disease by itself introduces a heterogenous group of patients to the sample by itself. Clearly, patients with resectable and non-resectable stage IV disease may represent entirely different subgroups of patients in regard to metastatic disease.

Third, overall survival may be a tricky endpoint. Other than colorectal cancer-related factors affecting overall survival that may be relevant players were not included in Quezada-Gutiér- 
rez's study. Comorbidities, for example, are not fully explored in the analysis. Overall survival is classically defined as a precise endpoint. ${ }^{4}$ However, being the single endpoint in such an analysis may be tricky, and can lead to bias in the final interpretation of the results. Other factors which are not necessarily cancer-related may negatively or positively affect survival rates and were not taken into account in the Mexican study.

We would challenge the readers that low levels of education can be associated with lower overall survival irrespective of having the diagnosis of any cancer in a given population. Therefore, in the absence of a clear association between levels of education and cancer specific survival, it may become impossible to definitively establish any meaningful association here.

Finally, an important point of the present study refers to the applicability of their findings. How is the patient population described in the Mexican analysis representative of any other? How is this population comparable to any other in terms of both education and oncological treatment for colorectal cancer?

Altogether, low levels of education may be associated with worse survival. However, we still do not know why. May low levels of education represent a marker for what specific features? Another question would be "to whom?" Is this really associated with this particular patient population or even to any colorectal cancer population? One should not deny what is obvious to see. However, do not simply assume that the obvious is true for different realities. A wider analysis regarding the association of low levels of education in different regions of the globe is warranted, and could elucidate, if existing, a causeeffect relation.

\section{FINANCIAL SUPPORT}

The authors received no financial support for the research, authorship, and/or publication of this article.

\section{CONFLICT OF INTEREST}

No potential conflict of interest relevant to this article were reported.

\section{AUTHOR CONTRIBUTION}

Writing and approval of final manuscript: Valiati B, Perez RO, Kotze PG.

\section{ORCID}

Valiati B https://orcid.org/0000-0003-4636-7708

Perez RO https://orcid.org/0000-0003-1704-2277

Kotze PG https://orcid.org/0000-0002-2053-5315

\section{REFERENCES}

1. Albano JD, Ward E, Jemal A, et al. Cancer mortality in the United States by education level and race. J Natl Cancer Inst 2007; 99:1384-1394.

2. Kelsall HL, Baglietto L, Muller D, Haydon AM, English DR, Giles GG. The effect of socioeconomic status on survival from colorectal cancer in the Melbourne Collaborative Cohort Study. Soc Sci Med 2009;68:290-297.

3. Quezada-Gutiérrez C, Álvarez-Bañuelos MT, Morales-Romero J, Sampieri CL, Guzmán-García RE, Montes-Villaseñor E. Factors associated with the survival of colorectal cancer in Mexico. Intest Res 2020;18:315-324.

4. Wilson MK, Karakasis K, Oza AM. Outcomes and endpoints in trials of cancer treatment: the past, present, and future. Lancet Oncol 2015;16:e32-e42. 